\title{
Differential expression of TIM-3 between primary and metastatic sites in renal cell carcinoma
}

Xingming Zhang ${ }^{1,2+}$, Xiaoxue Yin ${ }^{3 \dagger}$, Haoran Zhang ${ }^{1,2+}$, Guangxi Sun ${ }^{1,2}$, Yaojing Yang ${ }^{1,2}$, Junru Chen ${ }^{1,2}$, Kunpeng Shu ${ }^{1,2}$, Jinge Zhao ${ }^{1,2}$, Peng Zhao ${ }^{1,2}, \mathrm{Ni}_{\text {Chen }}{ }^{3}$, Jia Wang ${ }^{1,2}$, Pengfei Shen ${ }^{1,2^{*}}$ and Hao Zeng ${ }^{1,2^{*}}$ (D)

\begin{abstract}
Background: Due to the significant heterogeneity of renal cell carcinoma (RCC), immune checkpoints may express differently between primary and metastatic tumor. We aimed to evaluate the differential expression of TIM-3 between the primary and metastatic sites of RCC.

Methods: Cases of RCC with metastases resected or biopsied at West China Hospital between January 2009 and November 2016 were included. Clinicopathological parameters were retrospectively extracted. SPPS 22.0, GraphPad Prism 6 and R statistical software were applied for data analysis.

Results: A total of 163 cases were included. Immunohistochemical results showed that the overall detection rate of TIM-3 was $56.4 \%$ (92/163). The detection rate of TIM-3 in the primary $(53.0 \%, 44 / 83)$ was numerically higher than that of the metastasis $(42.6 \%, 79 / 174)$. Although the concordance rate of TIM-3 between the primary and metastasis was as high as 66.3\% (55/83) in the paired cohort, a significant statistically difference of TIM-3 expression between the primary and metastasis was observed $(X 2=4.664, p=0.002$ ), with a poor consistency (Kappa $=0.331, p=0.002$ ). Subsequent survival analysis suggested that TIM-3 expression either in the primary or metastatic tumor was associated with longer progression-free survival (PFS) (HR: $0.67,95 \% \mathrm{Cl} 0.45-0.99, P=0.02$ ) and overall survival (OS) (HR: $0.52,95 \% \mathrm{Cl} 0.33-0.82$, $P<0.001$ ). The expressions of TIM-3 in the primary, metastatic tumors and patients treated with targeted agents all played as favorable factors for PFS and OS. Further multivariate analysis showed that, in the whole cohort, TIM-3 expression in metastatic tumor increased the predicted accuracy (PA) of the whole model of PFS from 74.7 to $75.6 \%(P=0.02)$. For OS, the PA of whole model was increased from 78.1 to $81.1 \%$ by adding TIM-3 expression in the metastasis $(P=0.005)$. The same trends were also observed in paired patients and patients treated with targeted agents. In conclusion, the expression difference between the primary and metastatic tumor of TIM-3 was significant. Biopsy or resection of the metastases may provide a more accurate biological information for clinician's decision-making and the patient's prognosis. What's more, the role of TIM-3 in the RCC still remains controversy, further study are needed to verify the conclusion.
\end{abstract}

Keywords: Differential expression, Metastases, Primary tumor, Renal cell carcinoma, TIM-3

\footnotetext{
*Correspondence: cdhx510@foxmail.com; cdhx510@foxmail.com

${ }^{+}$Xingming Zhang, Xiaoxue Yin and Haoran Zhang contributed equally to

this work.

'Department of Urology, West China Hospital, Sichuan University, No. 37

Guoxue Xiang, Chengdu 610041, Sichuan, China

Full list of author information is available at the end of the article
}

C The Author(s). 2019 Open Access This article is distributed under the terms of the Creative Commons Attribution 4.0 International License (http://creativecommons.org/licenses/by/4.0/), which permits unrestricted use, distribution, and reproduction in any medium, provided you give appropriate credit to the original author(s) and the source, provide a link to the Creative Commons license, and indicate if changes were made. The Creative Commons Public Domain Dedication waiver (http://creativecommons.org/publicdomain/zero/1.0/) applies to the data made available in this article, unless otherwise stated. 


\section{Introduction}

Of all patients with kidney cancer, $20-30 \%$ of them were diagnosed as metastatic renal cell carcinoma (RCC) at initial diagnosis, and about $20-40 \%$ of localized renal cell carcinoma would develop distant metastasis in spite of having been treated with radical nephrectomy [1]. All along kidney cancer was recognized as immunogenic tumors. Thus in the 1990s, non-specific immunotherapy with cytokines was seen as the standard treatment of mRCC. However, due to the low efficacy of cytokine drugs, the objective response rate was only $5-27 \%$, and the median progression-free survival (PFS) was only $3-$ 5 months, accompanied by evident side effects. Compared with cytokines, targeted agents showed significant tumor response and beneficial survival outcomes. Nevertheless, the median survival time was still only 8-30 months (according to different prognostic risk group) [2-4]. Therefore, development of more effective drugs to improve patients' survival outcomes is needed.

Recent studies demonstrated that immune checkpoints have played key roles in the mechanism of immune escape [5-8]. In the tumor immunologic microenvironment, the most critical part of antitumor activity is the $\mathrm{T}$ cell activation. Activated $\mathrm{T}$ cells can effectively recognize and kill tumor cells. With the breakthroughs in molecular immunology, researchers have found the presence of a variety of co-stimulatory and co-inhibitory signal receptors-the two common regulation of $\mathrm{T}$ cell activation-on $\mathrm{T}$ cell surface [9]. The co-stimulatory signal receptor is like an "accelerator" to promote $\mathrm{T}$ cell activation, thereby facilitating the immune cells killing tumor cell. Co-inhibitory signal receptor is like a "brake" trigger leading to $\mathrm{T}$ cell inactivation by tumor cells using its immunological checkpoints to combine with co-inhibitory signal receptor. Ultimately, tumor cells survive, or rather the occurrence of immune escape [10].

Through analyzing the expression of immune checkpoints in tumor and the effect of checkpoints inhibitors, researchers found a positive correlation between immune checkpoints (such as PD-L1) over-expression and the treatment response in lung cancer and melanoma $[11,12]$. However, there was no such correlation observed in RCC [13]. Due to the significant heterogeneity of RCC, immune checkpoints may express differently between primary and metastatic tumor. This differential expression suggest that the evaluation of expressions of immune checkpoints in metastasis might offer more accurate prediction of treatment response of immunotherapy $[14,15]$. Several studies have shown that PD-L1 differentially expressed between the primary and metastasis in myeloma and RCC [14, 15]. However, it is unclear that whether TIM-3 (T cell immunoglobulin and mucindomain containing-3), another immune checkpoint, is in the same situation with that of PD-L1 in RCC.
TIM-3 is an immune checkpoint (co-inhibitory signal receptor) located in T-cell [16]. Despite the functional role of Tim-3 was first described to negatively regulate the Th1 response, it seems to play a more complicated

Table 1 Baseline clinicopathological parameters of included patients

\begin{tabular}{|c|c|c|c|}
\hline & Paired $(N=83)$ & Metastatic $(N=80)$ & $P$ value \\
\hline Age, n (\%) & & & 0.546 \\
\hline$<70$ & 76 (91.6) & $71(88.8)$ & \\
\hline$\geq 70$ & $7(8.4)$ & $9(11.2)$ & \\
\hline Gender, n (\%) & & & 0.873 \\
\hline Male & $54(65.1)$ & $53(66.3)$ & \\
\hline Female & $29(34.9)$ & 27 (33.7) & \\
\hline ISUP, n (\%) & & & 0.066 \\
\hline$<4$ & $49(67.1)$ & $58(80.6)$ & \\
\hline$\geq 4$ & $24(32.9)$ & $14(19.4)$ & \\
\hline Histological Type, n (\%) & & & 0.032 \\
\hline $\mathrm{CCRCC}$ & $59(71.1)$ & $68(61.3)$ & \\
\hline Non-ccRCC & $24(28.9)$ & $12(38.7)$ & \\
\hline \multicolumn{4}{|l|}{ Pathology, n (\%) } \\
\hline Sarcomatoid & $6(19.4)$ & $2(28.6)$ & 0.509 \\
\hline Necrosis & 25 (80.6) & $5(71.4)$ & 0.491 \\
\hline Nephrectomy, n (\%) & & & 0.001 \\
\hline Yes & $80(96.4)$ & $57(77.0)$ & \\
\hline No & $3(3.6)$ & $17(23.0)$ & \\
\hline ECOG, n (\%) & & & 0.801 \\
\hline $0-1$ & $53(70.7)$ & 59 (76.6) & \\
\hline$\geq 2$ & $22(29.3)$ & $18(23.4)$ & \\
\hline IMDC, n (\%) & & & 0.293 \\
\hline Low & $14(18.3)$ & $19(28.4)$ & \\
\hline Intermediate & $43(57.3)$ & $37(55.2)$ & \\
\hline High & $18(24.0)$ & $11(16.4)$ & \\
\hline T stage, n (\%) & & & 0.587 \\
\hline$<2 b$ & $46(59.7)$ & $12(66.7)$ & \\
\hline$\geq 2 b$ & $31(40.3)$ & $6(33.3)$ & \\
\hline \multicolumn{4}{|l|}{ Metastasis, n (\%) } \\
\hline Lung & $6(8.1)$ & $17(28.8)$ & 0.010 \\
\hline Brain & $7(9.5)$ & $12(20.3)$ & 0.192 \\
\hline Liver & $1(1.4)$ & $2(3.4)$ & 0.539 \\
\hline Bone & $18(24.3)$ & $22(37.3)$ & 0.389 \\
\hline Lymph node & $42(56.8)$ & $6(10.2)$ & 0.001 \\
\hline \multicolumn{4}{|l|}{ Treatment, n (\%) } \\
\hline Cytokine & 14 (16.9) & $8(10.0)$ & 0.345 \\
\hline Target therapy & $34(41.0)$ & $30(37.5)$ & 0.882 \\
\hline Radiotherapy & $7(8.4)$ & $7(8.8)$ & 0.673 \\
\hline Chemotherapy & $3(3.6)$ & $5(6.2)$ & 0.360 \\
\hline Unknown & $25(30.1)$ & $30(37.5)$ & \\
\hline
\end{tabular}


role in regulating anti-tumor response [16]. In fact, stimulation of Tim-3 is considered to act as both inhibitory and activating signal, which has been demonstrated in infectious diseases, autoimmune disorders and cancer immunity [17-20].

Therefore, in the present study, we aimed to compare the differential expression of TIM-3 in the primary and metastatic sites of RCC, and additionally, to find the role of TIM-3 in predicting patient's prognosis.

\section{Materials and methods}

\section{Patients and samples}

Cases of RCC histologically diagnosed by focal resection or fine needle aspiration at West China Hospital from January 2009 to November 2016 were included. The inclusion criteria were metastatic disease at initial diagnosis with metastasis resected or biopsied, with or without companying specimens of the primary tumor. The exclusion criteria were metastases which were only suspected of deriving from kidney cancer, without screening of evidence of the primary tumor, or with a negative result in screening. All included cases were independently diagnosed by two urological pathologists ( $\mathrm{Ni} \mathrm{Chen}$ and Xiaoxue Yin), and the paraffin blocks of included cases were screened suitable for immunohistochemical staining.

Clinicopathological parameters were retrospectively extracted, including age, gender, metastatic sites, $\mathrm{T}$ stage, Eastern Cooperative Oncology Group (ECOG) status,
International Metastatic Renal-Cell Carcinoma Database Consortium (IMDC) classification, ISUP grade, histological type, treatment, nephrectomy status and tumor necrosis. The end-points were PFS and OS. PFS was defined as the time from diagnosis to progression of disease or death. OS was defined as the time from diagnosis to all-cause death.

Expression of TIM-3 was detected by immunohistochemistry (IHC) by using anti-TIM-3 monoclonal antibody (Cell Signaling Technology, clone number: 45208S) at a 1:200 dilution. Positive signal of TIM-3 was on the cell membrane. Staining intensities were evaluated on a scale of 0 (null), $1+$ (weak), $2+$ (moderate) and $3+$ (strong) [14]. Positivity of TIM-3 was defined as the positive signal detected on $>5 \%$ tumor cells with staining intensity $\geq 1+$. All staining results were independently assessed by two urological pathologists (Ni Chen and Xiaoxue Yin).

\section{Data analysis}

SPPS 22.0, GraphPad Prism 6 and R statistical software were applied for data analysis. Continuous parameters were calculated as mean and SD and were analyzed by non-parametric test. Categorical parameters were calculated as proportions and were analyzed by chi-square test. Kappa test was applied to analyze the expression consistency between the primary and metastatic sites. The agreement was measured by Kappa coefficient:

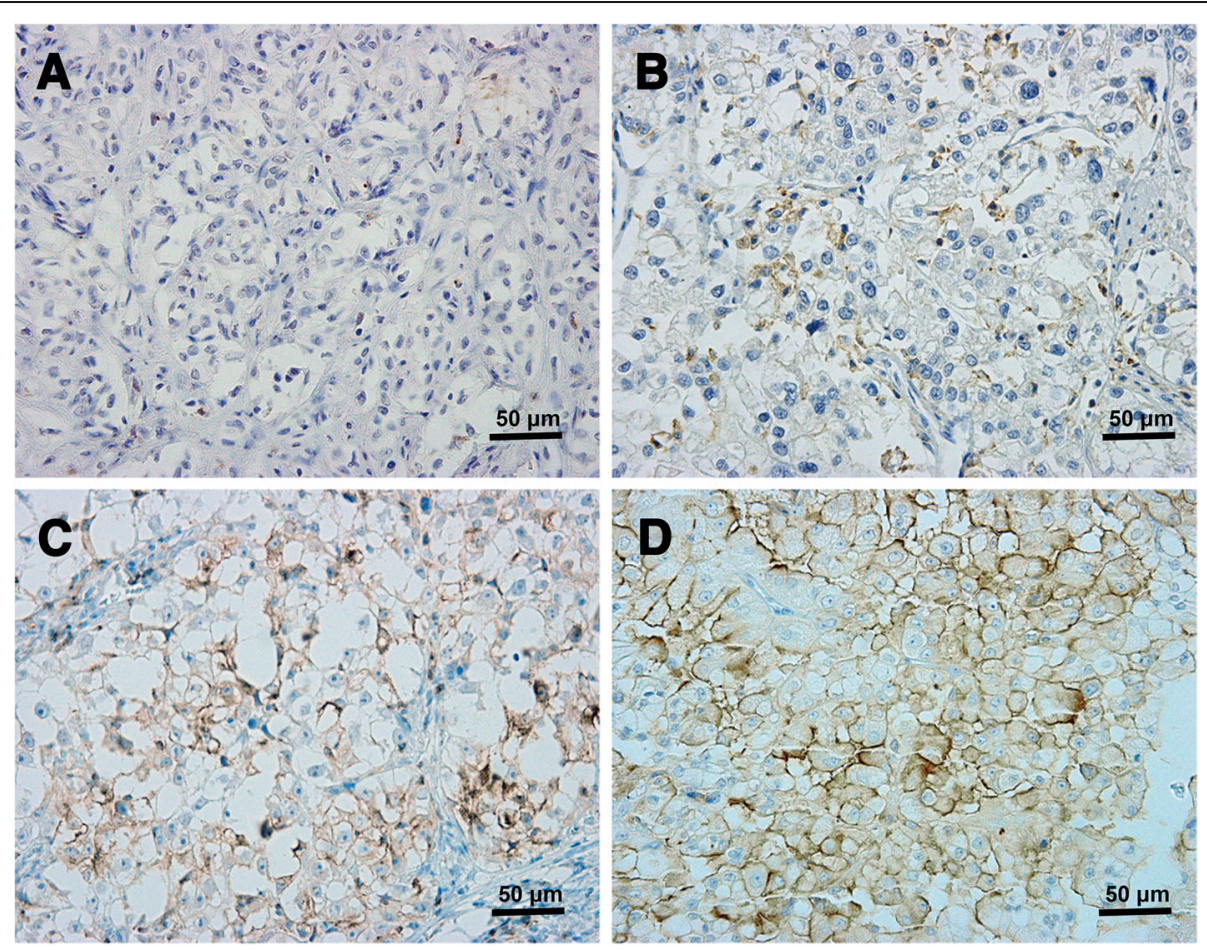

Fig. 1 Representative images of immunohistochemical staining of TIM-3. a represented negative expression of TIM-3. b, c and $\mathbf{d}$ represented different positive intensities (1+, 2+ and 3+) of TIM-3 (original magnification: 200X) 
Kappa $\leq 0.2$ as indicating slight agreement, $0.4<$ Kappa $\leq 0.6$ as fair, $0.6<$ Kappa $\leq 0.8$ as substantial, $>0.8$ as almost perfect agreement great. Kaplan-Meier and Cox's proportional hazards regression model were applied to analyze PFS and OS. $P<0.05$ was considered significant in all results. Predictive accuracy (PA) was calculated by using $R$ software. Kaplan-Meier and Cox's proportional hazards regression model were applied to analyze survival outcomes. Statistical significance was defined as $P<0.05$.

Table 2 Relationship between the expression of TIM-3 and clinicopathological parameters

\begin{tabular}{|c|c|c|c|}
\hline & \multicolumn{2}{|l|}{ TIM-3 } & \multirow[t]{2}{*}{$P$ value } \\
\hline & Positive & Negative & \\
\hline Total & $92(56.4)$ & $71(43.6)$ & \\
\hline Age, n (\%) & & & 0.987 \\
\hline$<70 y$ & $83(90.2)$ & $64(90.1)$ & \\
\hline$\geq 70 y$ & $9(9.8)$ & $7(9.9)$ & \\
\hline Gender, n (\%) & & & 0.259 \\
\hline Male & $57(53.3)$ & $50(46.7)$ & \\
\hline Female & $35(62.5)$ & $21(37.5)$ & \\
\hline ISUP, n (\%) & & & 0.055 \\
\hline$<4$ & $67(79.8)$ & $40(65.6)$ & \\
\hline$\geq 4$ & $17(20.2)$ & $21(34.4)$ & \\
\hline Histological Type, n(\%) & & & 0.377 \\
\hline cCRCC & $74(58.3)$ & $53(41.7)$ & \\
\hline Non-ccRCC & $18(50.0)$ & $18(50.0)$ & \\
\hline \multicolumn{4}{|l|}{ Pathology, n (\%) } \\
\hline Sarcoma & $5(62.5)$ & $3(37.5)$ & 0.898 \\
\hline Necrosis & $20(66.7)$ & $10(33.3)$ & 0.958 \\
\hline Nephrectomy & & & 0.026 \\
\hline Yes & $84(61.3)$ & $53(38.7)$ & \\
\hline No & $7(35.0)$ & $13(65.0)$ & \\
\hline ECOG, n (\%) & & & 0.239 \\
\hline $0-1$ & $68(60.7)$ & $44(39.3)$ & \\
\hline$\geq 2$ & $20(50.0)$ & $20(50.0)$ & \\
\hline IMDC, n (\%) & & & 0.030 \\
\hline Low & $23(69.7)$ & $10(30.3)$ & \\
\hline Intermediate & $49(61.3)$ & $31(38.7)$ & \\
\hline High & $11(37.9)$ & $18(62.1)$ & \\
\hline T stage, n (\%) & & & 0.391 \\
\hline$<2 b$ & $38(64.4)$ & $20(55.6)$ & \\
\hline$\geq 2 b$ & $21(35.6)$ & $16(44.4)$ & \\
\hline \multicolumn{4}{|l|}{ Treatment, n (\%) } \\
\hline Cytokine & $12(54.5)$ & $10(45.5)$ & 0.762 \\
\hline Targeted therapy & $32(50.0)$ & $32(50.0)$ & 0.088 \\
\hline Radiotherapy & $7(50.0)$ & $7(50.0)$ & 0.504 \\
\hline Chemotherapy & $5(62.5)$ & $3(37.5)$ & 0.817 \\
\hline
\end{tabular}

Predictive accuracy (PA) was calculated by using $\mathrm{R}$ software.

\section{Results}

Baseline characteristics of included patients

A total of 163 patients were included in this study from January, 2009 to November, 2016 in West China Hospital, Sichuan University. Patients' characteristics were summarized in Table 1 . There were 83 paired cases (both primary and metastatic tumors were available) and 80 cases of metastatic tumors with no accompanied primary tumors.

\section{Expressions of TIM-3 in the whole and paired cohort}

Figure 1a showed negative expression of TIM-3 in RCC tumor. TIM-3 was mainly expressed on the membrane of tumor cells (Fig. 1b-d). In the whole cohort $(N=163)$, the overall detection rate of TIM-3 was $56.4 \%(92 / 163)$. The associations between clinical pathological parameters and TIM- 3 expression in the primary or metastatic tumor were shown in Table 2. TIM-3 expression in patients with nephrectomy was higher that of patients without nephrectomy $(\mathrm{X} 2=4.96, p=0.03)$. After stratified by IMDC classification, a gradually decreasing trend of the detection rates was observed from favorable (69.7\%), intermediate (61.3) to high risk (37.9\%) groups ( $\mathrm{x}^{2}=7.01, P=0.03$ ).

As shown in Table 3, immunohistochemistry results suggested numerically differential expression of TIM-3 between the primary and metastatic tumors, with a higher detection rate in the primary than that in the metastasis ( $53.0 \%$ vs $45.4 \%)$. However, TIM-3 was homogeneously expressed among different metastatic sites, with no significant difference to the primary tumor except for bone metastasis, which was lower than primary tumor

Table 3 Differential expressions of TIM-3 between the primary and metastatic tumors

\begin{tabular}{lllll}
\hline & \multicolumn{2}{l}{ TIM-3, N(\%) } & P value \\
\cline { 2 - 4 } & $\mathrm{N}$ & Positive & Negative & \\
\hline Primary & 83 & $44(53.0)$ & $39(47.0)$ & \\
Metastasis $^{\mathrm{a}}$ & 163 & & & \\
Total & 175 & $79(45.4)$ & $95(54.6)$ & 0.253 \\
Lung/lymph node & 72 & $32(44.4)$ & $40(55.6)$ & 0.287 \\
Lung & 24 & $12(50.0)$ & $12(50.0)$ & 0.795 \\
Lymph node & 46 & $20(43.5)$ & $26(56.5)$ & 0.300 \\
Bone & 41 & $16(39.0)$ & $25(61.0)$ & 0.143 \\
Brain & 19 & $8(42.1)$ & $11(57.9)$ & 0.391 \\
Viscera without lung & 14 & $11(78.6)$ & $3(21.4)$ & 0.074 \\
Ipsilateral Adrenal gland & 4 & $3(75.0)$ & $1(25.0)$ & 0.389 \\
Others & 20 & $7(35.0)$ & $13(65.0)$ & 0.148 \\
\hline 12 cases have two metastatic sites & & &
\end{tabular}


$\left(\mathrm{X}^{2}=5.98, p=0.01\right)$. The expression rates of different metastatic sites were (from high to low): viscera without lung $(78.6 \%, 11 / 14)$, ipsilateral adrenal gland $(75 \%, 3 / 4)$, lung/lymph node $(44.4 \%, 32 / 72)$, brain $(42.1 \%, 8 / 19)$, others $(35.0 \%, 7 / 20)$ and bone $(39.0 \%, 16 / 41)$.

In the paired cohort $(N=80)$, the concordance rate of TIM-3 between the primary and metastasis was $66.3 \%$ (55/83). However, TIM-3 was differentially expressed between the primary and metastasis, with a significant statistically difference $\left(\mathrm{X}^{2}=4.66, p=0.03\right)$ and poor consistency $($ Kappa $=0.23, \mathrm{p}=0.03)$.

\section{Associations of TIM-3 expression with clinical outcomes}

The median PFS was 23.0 months (IQR:9.0-46.0), and the median OS was 36.0 month (IQR:16.0-70.0). In 64 patients with TKI therapy, the median PFS and OS were

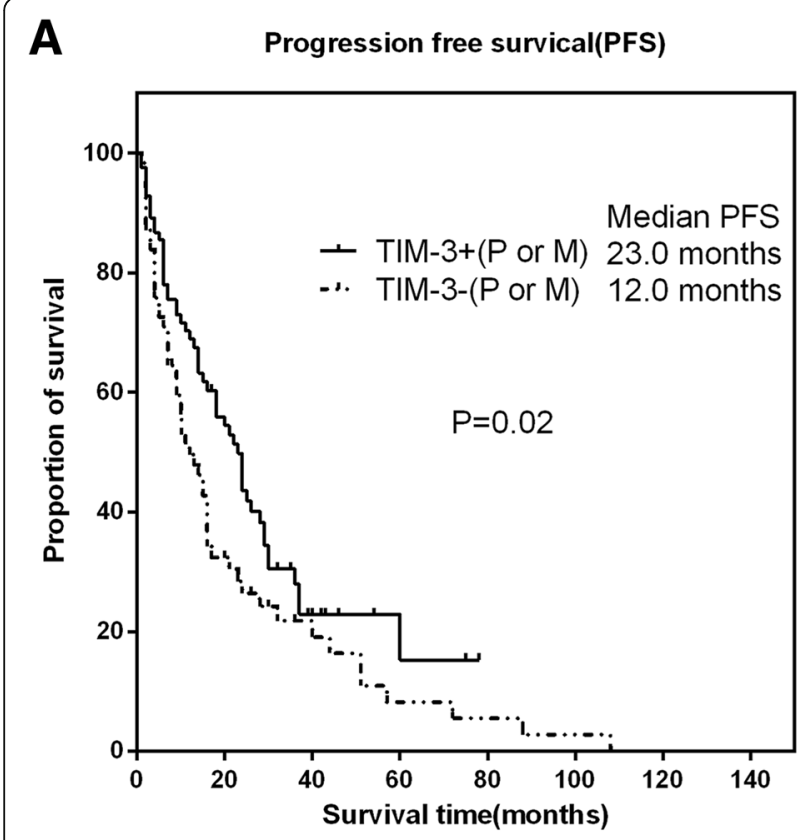

B

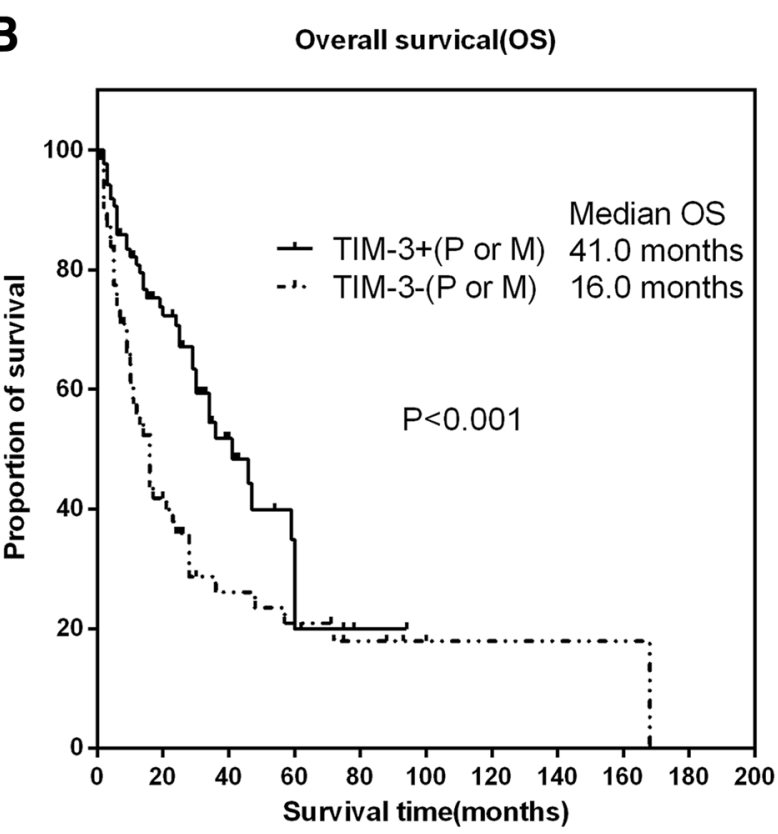

C

Progression free survical(PFS)

D

Overall survical(OS)
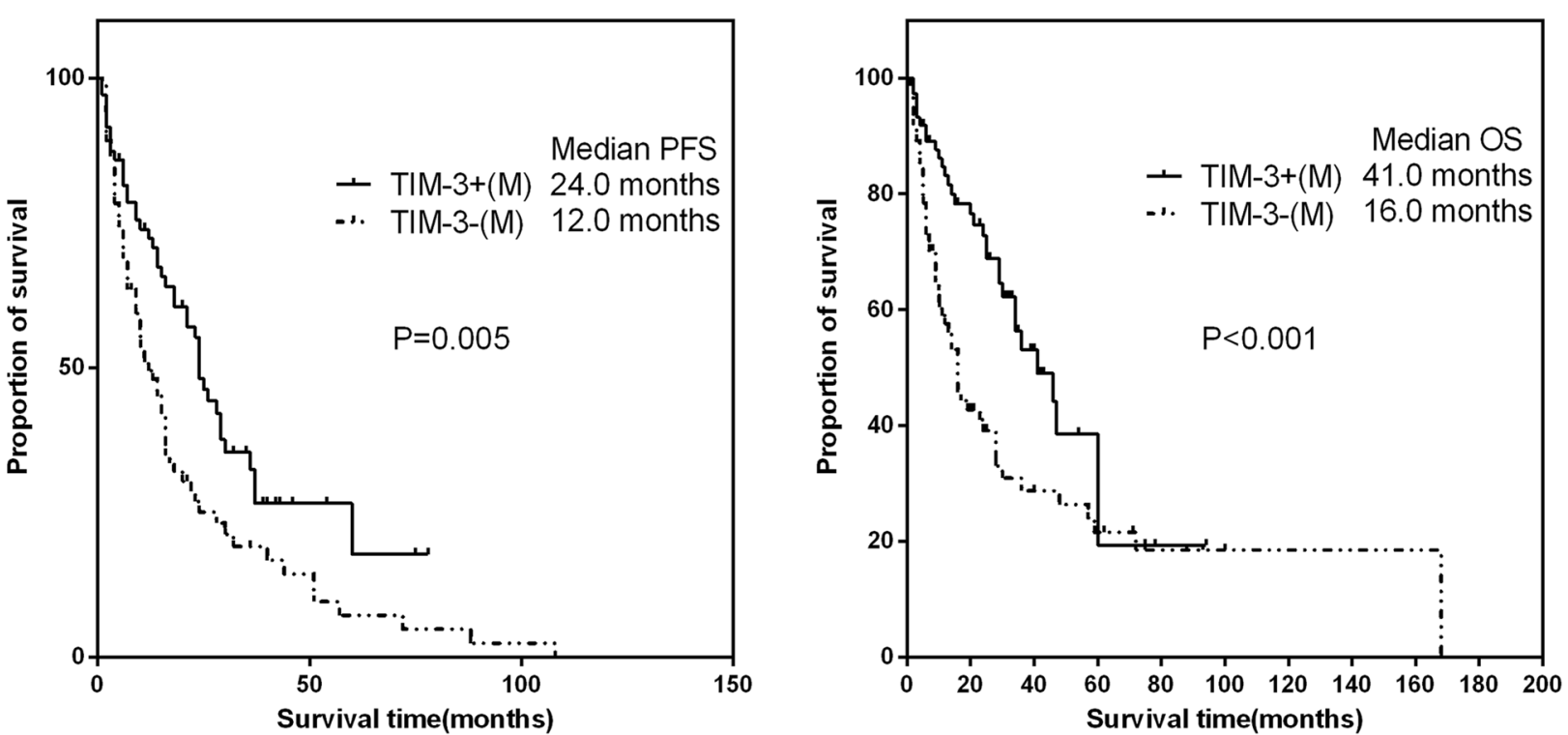

Fig. 2 The associations of TIM-3 expressions with clinical outcomes in all patients with RCC. Representative images of kaplan-Meier survival curves of TIM-3 expression. a (PFS) and $\mathbf{b}$ (OS) represented TIM-3 expression either in the primary or metastatic tumor; $\mathbf{c}$ (PFS) and $\mathbf{d}$ (OS) represented TIM-3 expression in the metastatic tumor 
A

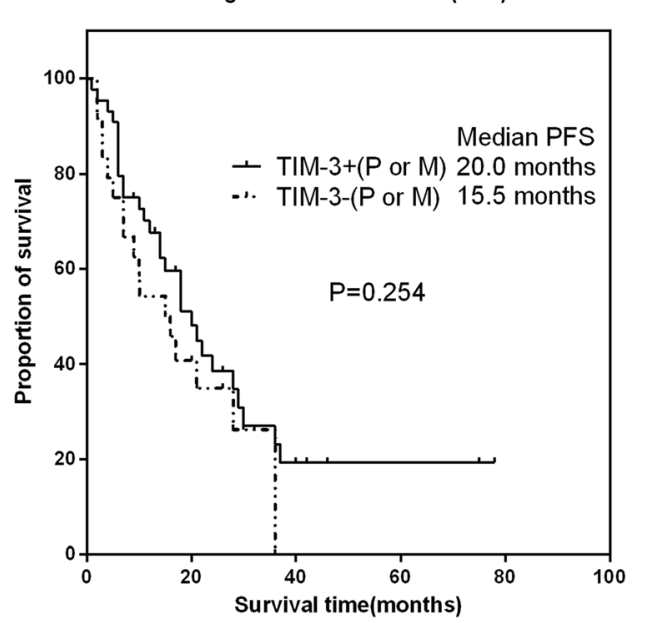

C

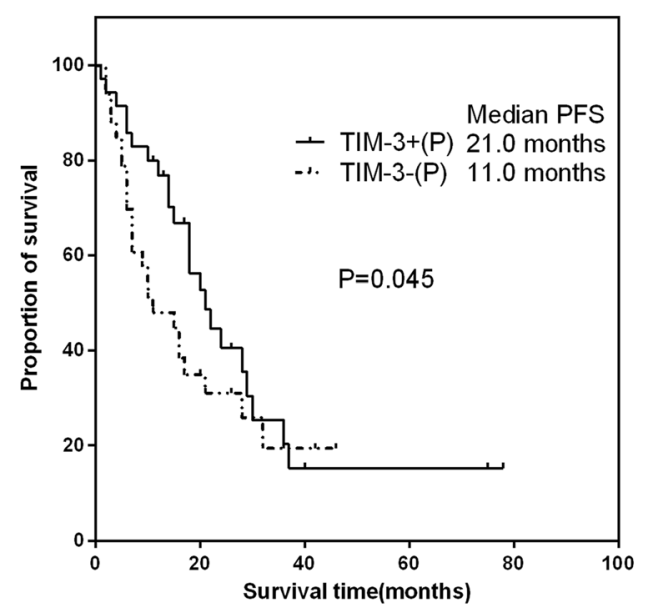

$\mathbf{E}$

Progression free survical(PFS)

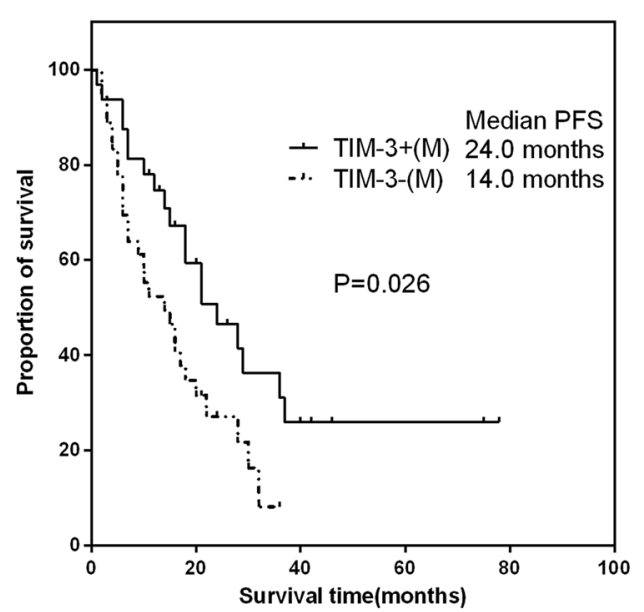

B

Overall survical(OS)

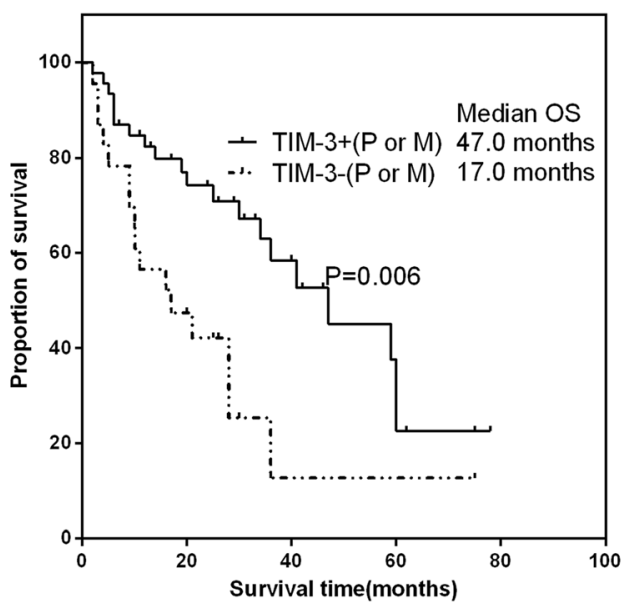

D

Overall survical(OS)

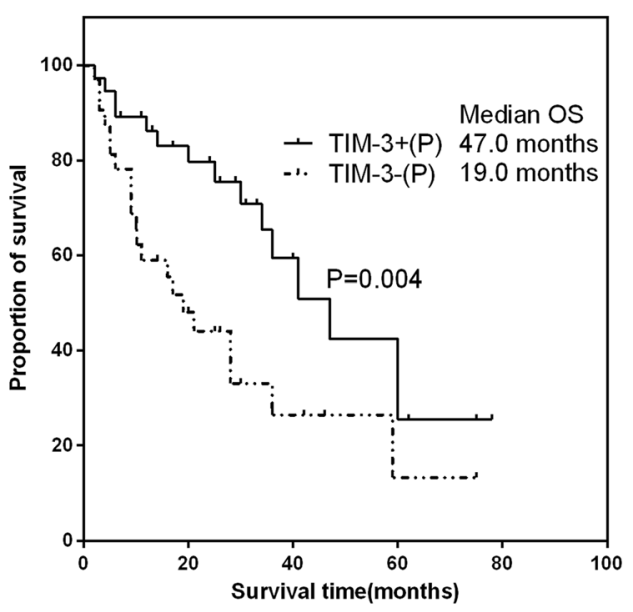

$\mathbf{F}$

Overall survical(OS)

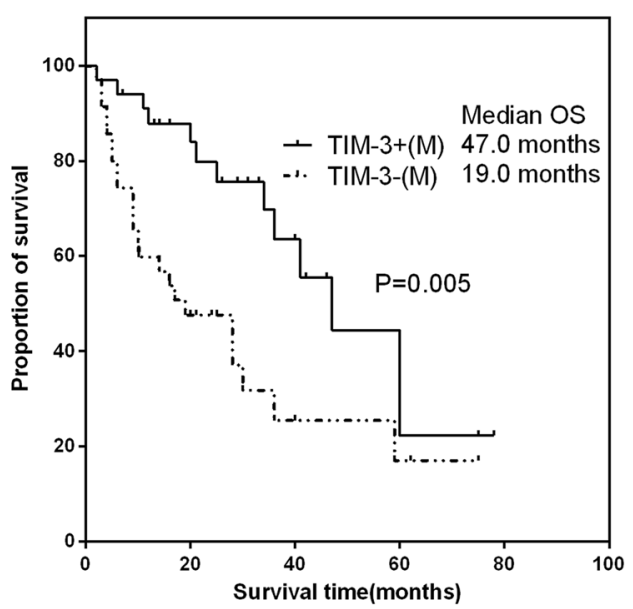

Fig. 3 The associations of TIM-3 expressions with clinical outcomes in paired patients with RCC. Representative images of kaplan-Meier survival curves of TIM-3 expression. a (PFS) and $\mathbf{b}$ (OS) represented TIM-3 expression either in the primary or metastatic tumor; $\mathbf{c}$ (PFS) and $\mathbf{d}(\mathrm{OS})$ represented TIM-3 expression in the primary tumor; $\mathbf{e}$ (PFS) and $\mathbf{f}(\mathrm{OS})$ represented TIM-3 expression in the metastatic tumor 
21.0 and 52.0 months, respectively. Subsequent survival analysis, as shown in Fig. 2a-b, suggested that TIM-3 expression either in the primary or metastatic tumor was associated with longer PFS (HR: 0.67, 95\% CI 0.45-0.99, $P=0.02$ ) and OS (HR: 0.52, 95\% CI 0.33-0.82, $P<0.001$ ). In the metastatic tumors, patients with TIM-3 expression experienced longer PFS (HR:0.59, 95\% CI 0.39-0.88, $P=$
0.005) and OS (HR: 0.51, 95\% CI 0.32-0.81, $P<0.001$ ) than that with negative expression (Fig. 2c-d).

As shown in Fig. 3a-b, in the paired cohort, TIM-3 expression in the primary or metastatic tumor was not associated with PFS (HR:0.684, 95\% CI 0.392-1.194, $P=0.254$ ), except for OS (HR: 0.4, 95\% CI 0.206-0.787, $P=0.006)$. Furthermore, TIM-3 expressions in the

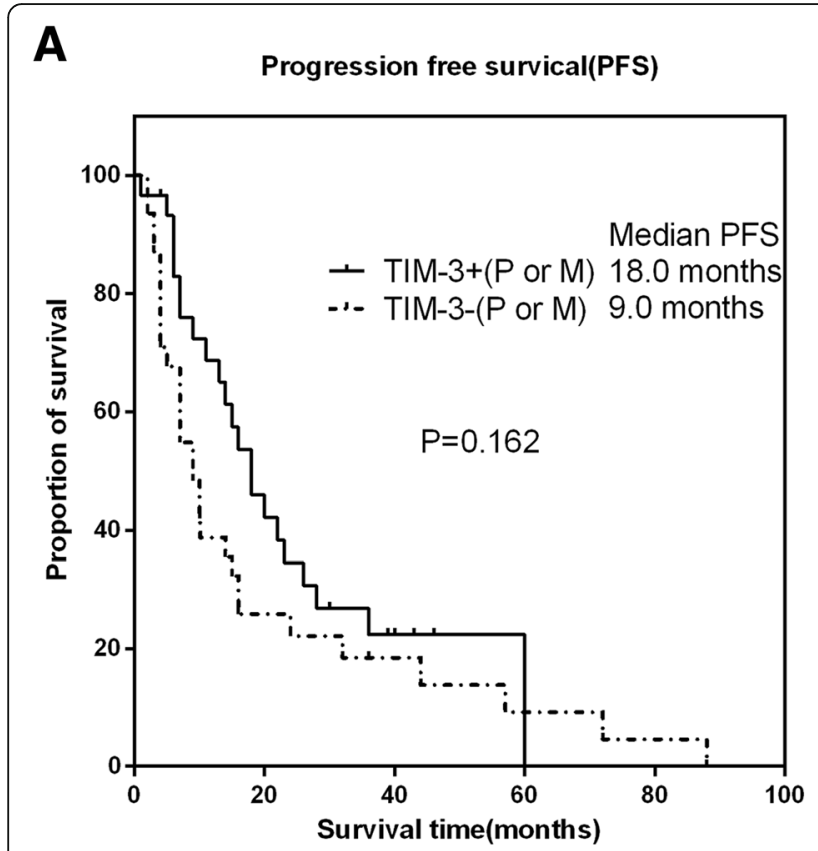

B
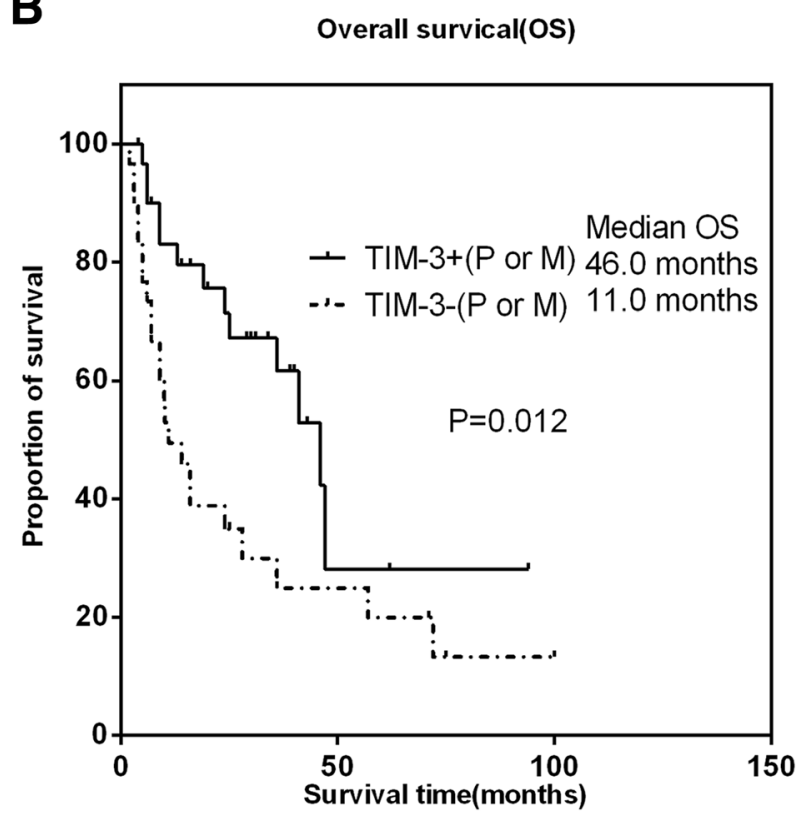

C

Progression free survical(PFS)

D Overall survical(OS)
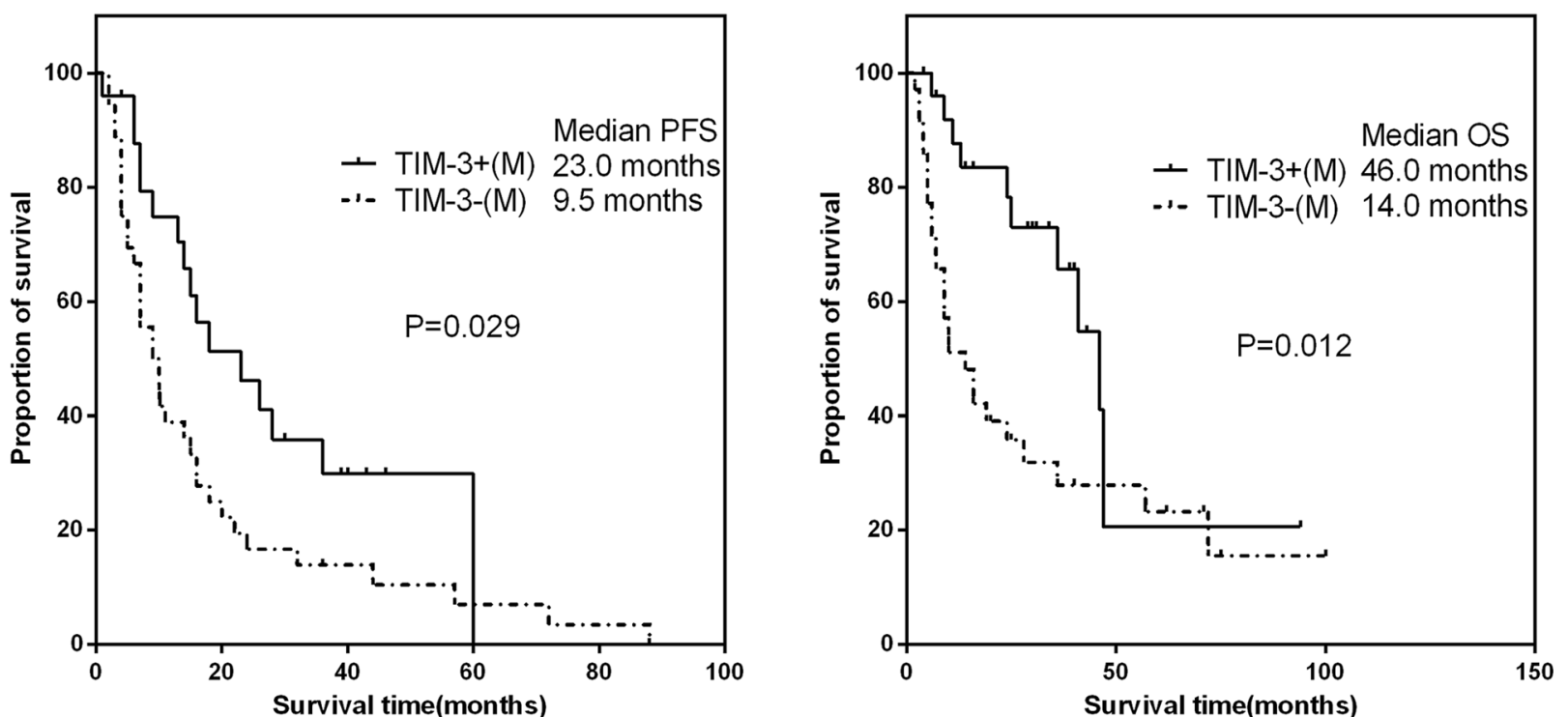

Fig. 4 The associations of TIM-3 expressions with clinical outcomes in targeted agents treated patients with RCC. Representative images of kaplan-Meier survival curves of TIM-3 expression. a (PFS) and $\mathbf{b}$ (OS) represented TIM-3 expression either in the primary or metastatic tumor; $\mathbf{c}(\mathrm{PFS})$ and $\mathbf{d}$ (OS) represented TIM-3 expression in the metastatic tumor 
primary and metastatic tumors were all associated with longer PFS and OS (Fig. 3c-f).

Additionally, TIM-3 expression was also positively correlated with PFS and OS in patients treated with targeted agents (Fig. 4). However, as shown in Fig. 4a, TIM-3 positive either in the primary or metastatic tumor was not associated with PFS $(P=0.162)$.

\section{Multivariate analysis of PFS and OS in the whole, paired and targeted cohort}

Unvariate analysis of PFS and OS in the three cohorts were performed (data not shown). Further multivariate analysis showed that, in the whole cohort, TIM-3 expression in metastatic tumor increased the predicted accuracy (PA) of the whole model of PFS from 74.7 to $75.6 \%(P=0.02$, Table 4$)$. For OS, the PA of whole model was increased from 78.1 to $81.1 \%$ by adding TIM-3 expression in the metastasis $(P=0.005$, Table 4$)$. In the paired cohort, TIM-3 expression in metastatic tumor increased the PA of the whole models of PFS from 71.5 to $74.5 \%(P<0.001)$ and OS from 78.2 to $81 \%(P=0.015$, Table 5). A same trend was also observed in patients treated with targeted agents: TIM-3 expression in the metastatic tumors significantly increased the PA values

Table 4 Multivariate analysis of PFS and OS in all patients $(N=163)$

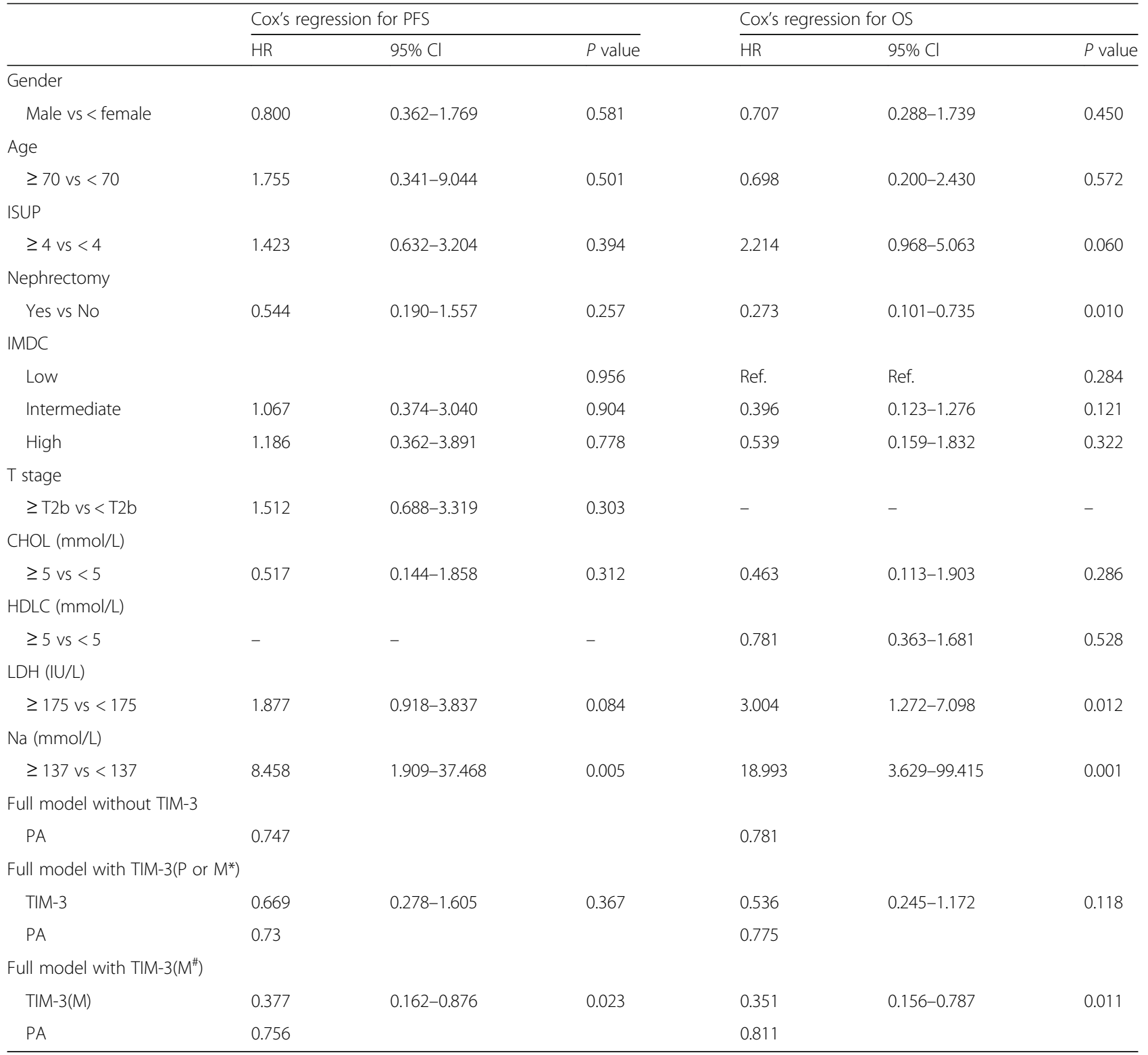

For PFS, the $P$ values for Full model with TIM-3(M) and TIM-3(P or M) compared to that without TIM-3 were 0.02 and 0.334 , respectively For OS, the $P$ values for Full model with TIM-3(M) and TIM-3(P or M) compared to that without TIM-3 were 0.005 and 0.126 , respectively *P or $M$, primary or metastatic tumor; ${ }^{\#} M$, metastatic tumor 
Table 5 Multivariate analysis of PFS and OS in paired patients $(N=83)$

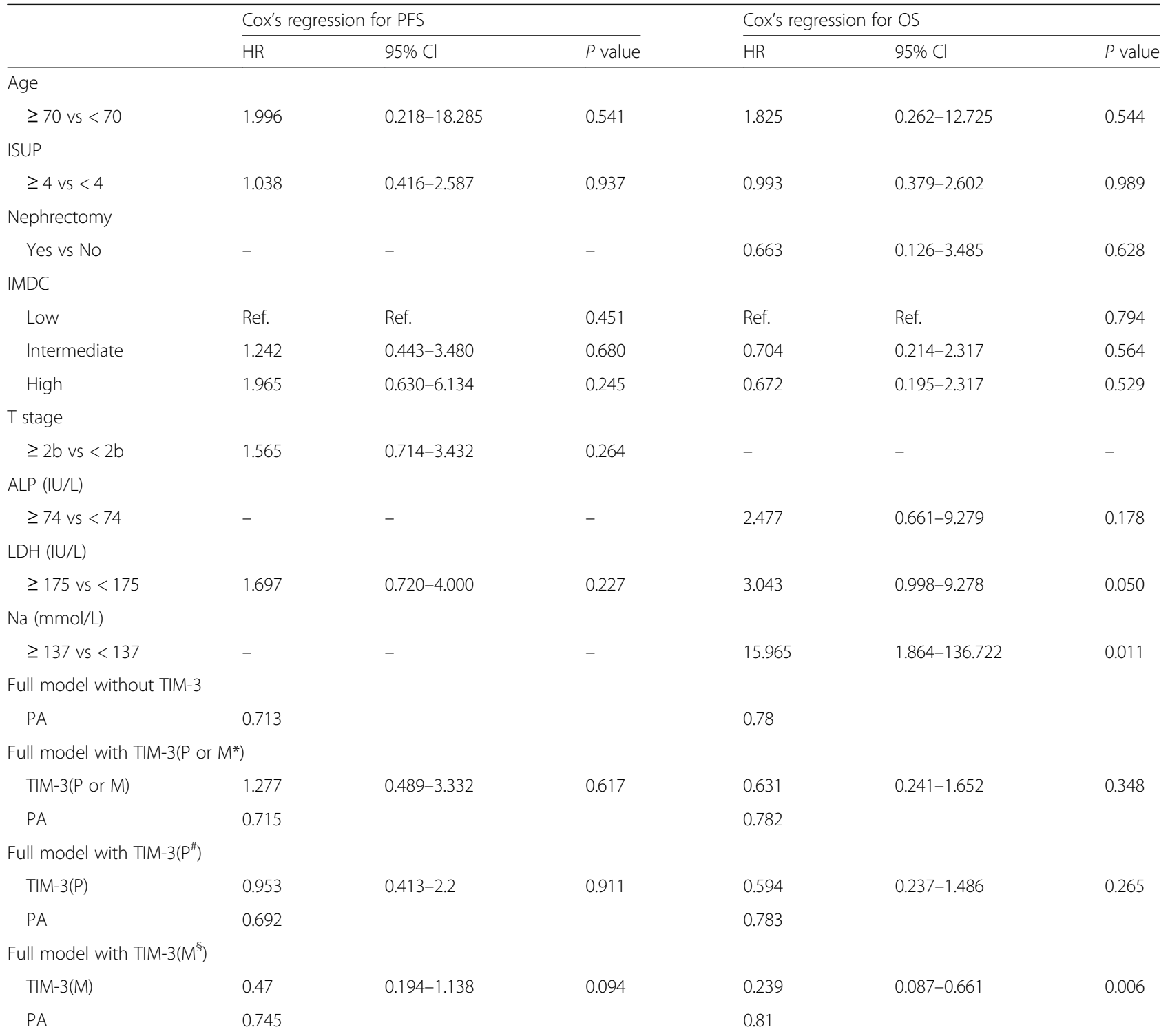

For PFS, the $P$ values for Full model with TIM-3(M), TIM-3(P or M) and TIM-3 (P) compared to that without TIM-3 were $<0.001,0.126$ and 0.098 , respectively For OS, the $P$ values for Full model with TIM-3(M), TIM-3(P or M) and TIM-3 $(P)$ compared to that without TIM-3 were $0.015,0.211$ and 0.206 , respectively

${ }^{*} \mathrm{P}$ or $\mathrm{M}$, primary or metastatic tumor; ${ }^{\#} \mathrm{P}$, primary tumor; ${ }^{\S} \mathrm{M}$, metastatic tumor

of PFS (from 73.5 to $79.1 \%, P=0.006$ ) and OS (from 84.2 to $87.3 \%, P=0.009$ ) models (Table 6).

\section{Discussion}

This was the first study that aimed to analyze the differential expressions of TIM-3 between the primary and metastatic tumors among mRCC patients. Meanwhile, based on the analyses of correlation and survival, we determined the relationship between the expression of TIM-3 and clinicopathological parameters, and its value in predicting patient's prognosis.

Researchers have found a positive correlation between immune checkpoints (such as PD-L1) expression and treatment effect in lung cancer and melanoma [11, 12], but there was no such correlation in RCC [13]. Furthermore, published evidences have demonstrated significant differential expressions of immune checkpoints between the primary and metastatic tumors [14, 21]. TIM-3 is one of these immune checkpoints and is located in T-cell [16]. Due to the significant heterogeneity of RCC, immunological factors like TIM-3 might express differently between primary and metastatic tumors.

The expressions of TIM-3 either in the primary or metastasis suggested a better prognosis for mRCC patients in our study, especially, its expression in metastases could more accurately predict the prognosis of patients 
Table 6 Multivariate analysis of PFS and OS in targeted agents treated patients $(N=64)$

\begin{tabular}{|c|c|c|c|c|c|c|}
\hline & \multicolumn{3}{|c|}{ Cox's regression for PFS } & \multicolumn{3}{|c|}{ Cox's regression for OS } \\
\hline & $\overline{\mathrm{HR}}$ & $95 \% \mathrm{Cl}$ & $P$ value & $\overline{\mathrm{HR}}$ & $95 \% \mathrm{Cl}$ & $P$ value \\
\hline \multicolumn{7}{|l|}{ ISUP } \\
\hline$\geq 4$ vs $<4$ & 1.082 & $0.363-3.232$ & 0.887 & 1.826 & $0.611-5.456$ & 0.281 \\
\hline \multicolumn{7}{|l|}{ Nephrectomy } \\
\hline Yes vs No & 0.081 & $0.016-0.408$ & 0.002 & 0.066 & $0.014-0.299$ & $<0.001$ \\
\hline \multicolumn{7}{|l|}{ ECOG } \\
\hline$\geq 2$ vs $<2$ & 1.131 & $0.382-3.345$ & 0.825 & 1.566 & $0.428-5.721$ & 0.498 \\
\hline \multicolumn{7}{|l|}{ IMDC } \\
\hline Low & 1 & Ref. & 0.860 & 1 & Ref. & 0.108 \\
\hline Intermediate & 1.195 & $0.300-4.760$ & 0.800 & 0.302 & $0.055-1.646$ & 0.166 \\
\hline High & 1.590 & $0.283-8.938$ & 0.599 & 1.525 & $0.268-8.664$ & 0.634 \\
\hline \multicolumn{7}{|l|}{ Time from diagnosis to metastasis } \\
\hline Synchronous vs Metachronous & 0.534 & $0.186-1.535$ & 0.244 & - & - & - \\
\hline T stage & & & & - & - & - \\
\hline$\geq 2 b$ vs $<2 b$ & 3.438 & $0.990-11.937$ & 0.052 & - & - & - \\
\hline \multicolumn{7}{|l|}{ ALP (IU/L) } \\
\hline$\geq 78$ vs $<78$ & - & - & - & 1.018 & $1.003-1.034$ & 0.021 \\
\hline \multicolumn{7}{|l|}{$\mathrm{Na}(\mathrm{mmol} / \mathrm{L})$} \\
\hline$<137$ vs $\geq 137$ & 18.258 & $1.506-221.386$ & 0.023 & 0.999 & $0.997-1.001$ & 0.336 \\
\hline \multicolumn{7}{|l|}{ Full model without TIM-3 } \\
\hline PA & 0.735 & & & 0.842 & & \\
\hline \multicolumn{7}{|l|}{ Full model with TIM-3(P or $\left.M^{*}\right)$} \\
\hline TIM-3(P or M) & 0.456 & $0.147-1.416$ & 0.174 & 0.755 & $0.296-1.926$ & 0.556 \\
\hline PA & 0.738 & & & 0.844 & & \\
\hline \multicolumn{7}{|l|}{ Full model with TIM-3(M $\mathrm{M}^{\#}$} \\
\hline TIM-3(M) & 0.167 & $0.048-0.586$ & 0.005 & 0.537 & $0.226-1.277$ & 0.159 \\
\hline PA & 0.791 & & & 0.873 & & \\
\hline
\end{tabular}

For PFS, the $P$ values for Full model with TIM-3(M) and TIM-3(P or M) compared to that without TIM-3 were 0.006 and 0.141 , respectively For OS, the $P$ values for Full model with TIM-3(M) and TIM-3(P or M) compared to that without TIM-3 were 0.009 and 0.216 , respectively

*P or $M$, primary or metastatic tumor; ${ }^{\#} M$, metastatic tumor

(with higher PA values both in PFS and OS models). Interestingly, the results of TIM-3 expression in predicting better prognosis of mRCC were contradictory to other tumors [22-26]. The exact reason of this phenomenon observed in mRCC remains unclear. According to our analysis about current reported studies, the possible reasons might include: 1) Most studies reported the prognostic role of TIM-3 in localized RCC, and TIM-3 may play different roles in different tumor stages; 2) Current evidences on the relationship between TIM-3 expression and prognosis are controversial among different tumor types. A study reported that TIM-3 was a protective factor in acute myeloid leukemia [20]. The same results were seen in pancreatic cancer, prostate cancer, usual vulvar intraepithelial neoplasia and colorectal cancer [27-30]. Additionally, in the ESMO 2017, Torras et al. reported that TIM-3 was differentially expressed between sunitinib refractory and sensitive groups, and was associated with benefit to sunitinib treatment in mRCC patients [31]. 3) The functional outcomes were different depending on the expressions of immune check points in tumor or tumor infiltrating immune cells. High expression of CTLA- 4 on CD8 + T cells was associated with shorter OS, but TIM-3 was positively correlated with prolonged OS when expressed on CD4 $+\mathrm{T}$ cells [27]. 4) Different biological functions of TIM-3 might be related to different expression localization. Similar to PD-1, TIM-3 was mainly expressed in cellular membranes, but it was also expressed in the nucleus in prostate cancer and colorectal cancer $[28,30]$. In bladder cancer and esophageal cancer, TIM-3 was both expressed in cellular membranes and cytoplasm [24, 32]. 5) TIM-3 also appears as a co-stimulatory signal in other nontumor disease states [18-20]. 
In fact, the mechanism of TIM-3 in anti-tumor immune responses is complex. Some studies showed that TIM-3 could act as a co-stimulatory signal receptor and enhance the killing effect of cytotoxic $\mathrm{T}$ cells and other immune cells [17-19]. Other studies also showed that TIM-3 might act as a "rheostat," thus orderly fine-tuning cellular responses [16]. It is unclear under what circumstances TIM-3 could appear to be co-suppressed or co-stimulatory signals, and whether co-suppression signals depend on the co-expression of other molecules still needs further validation, such as Ceacam-1 or crosstalk between different ligands of TIM-3 [16].

Multivariate analysis of the present study suggested that the expression of TIM- 3 in metastases was significantly higher than that in primary tumors in predicting the prognosis of patients. It was further clarified that the expression of TIM-3 in metastatic tumors might be more indicative to patient's prognosis. Therefore, more attention should be paid to the assessment of metastatic sites in clinical practice and research, to improve the efficacy of immunotherapy for mRCC and finally realize individualized treatment strategy.

This study was the first to evaluate the differential expression of TIM-3 in primary and metastatic RCC tumors, and is the largest study to date. However, this study still has the following limitations: 1) retrospective study design, which may induce potential selection bias; 2) limited number of paired patients; 3 ) different types of samples were included (frozen, resection and aspiration). Therefore, subsequent studies should focus on the observation of differences between expression and prognosis on different types of tumor.

\section{Conclusions}

The expression differences of TIM-3 were significant between the primary and metastatic tumors. The assessment of immunological checkpoint-related protein in primary tumor might not be able to provide adequate information for clinicians to evaluate or predict the patient's treatment-related efficacy and prognosis. The expressions of immune check points in metastatic lesions of mRCC should be given more attention, and their accurate diagnosis might be one of the effective ways to realize individual treatment. What's more, the role of TIM-3 plays in mRCC remains to be verified.

\footnotetext{
Abbreviations

ECOG: Eastern Cooperative Oncology Group; IHC: Immunohistochemistry; IMDC: International Metastatic Renal-Cell Carcinoma Database Consortium; mRCC: Metastatic Renal Cell Carcinoma; OS: Overall Survival; PA: Predicted Accuracy; PFS: Progression-Free Survival; RCC: Renal Cell Carcinoma; TIM-3: T cell immunoglobulin and mucin-domain containing-3
}

\section{Acknowledgements}

The authors would like to thank Ms. Junya Tan for giving technical support in immunohistological staining.

\section{Funding}

This work was supported by Natural Science Foundation of China (NSFC 81672547 and 81402110), Science and Technology Support Program of Sichuan Province (2015SZ0230-3) and 1.3 .5 project for disciplines of excellence, West China Hospital, Sichuan University (No.0040205301E21).

\section{Availability of data and materials}

All data generated or analyzed during the present study are included in this published article. The authors declare that materials described in the manuscript, including all relevant raw data, will be freely available to any scientist wishing to use them for non-commercial purposes, without breaching participant confidentiality.

\section{Authors' contributions}

$X Z$, PS and HZeng designed the experiments, $X Z, X Y$ and HZhang performed the experiments. XZ, GX, JC, KS, JG, PZ and NC collected clinicopathological data. $X Z, G S, X Y$ and $Y Y$ analyzed the results. $X Z$ and $Y Y$ generated the data, prepared the figures and Tables. XT, PS and JW wrote the manuscript. All authors have reviewed and approved the final version of the manuscript.

\section{Ethics approval and consent to participate}

The protocol of the present study, involving human clinical samples, was approved by the Ethics Committee of West China Hospital, Sichuan University. Written informed consent was obtained from all patients.

\section{Consent for publication}

Not applicable.

\section{Competing interests}

The authors declare that they have no competing interests.

\section{Publisher's Note}

Springer Nature remains neutral with regard to jurisdictional claims in published maps and institutional affiliations.

\section{Author details}

${ }^{1}$ Department of Urology, West China Hospital, Sichuan University, No. 37 Guoxue Xiang, Chengdu 610041, Sichuan, China. ${ }^{2}$ Institute of Urology, West China Hospital, Sichuan University, Chengdu, People's Republic of

China610041. ${ }^{3}$ Department of Pathology, West China Hospital, Sichuan University, Chengdu, People's Republic of China 610041.

Received: 17 October 2018 Accepted: 2 January 2019

Published online: 10 January 2019

References

1. Janzen NK, Kim HL, Figlin RA, Belldegrun AS. Surveillance after radical or partial nephrectomy for localized renal cell carcinoma and management of recurrent disease. Urol Clin North Am. 2003;30(4):843-52.

2. Fyfe G, Fisher RI, Rosenberg SA, Sznol M, Parkinson DR, Louie AC. Results of treatment of 255 patients with metastatic renal cell carcinoma who received high-dose recombinant interleukin-2 therapy. J Clin Oncol. 1995;13(3):688-96.

3. McDermott DF, Regan MM, Clark Jl, Flaherty LE, Weiss GR, Logan TF, Kirkwood JM, Gordon MS, Sosman JA, Ernstoff MS, et al. Randomized phase III trial of high-dose interleukin-2 versus subcutaneous interleukin-2 and interferon in patients with metastatic renal cell carcinoma. J Clin Oncol. 2005; 23(1):133-41.

4. Motzer RJ, Hutson TE, Tomczak P, Michaelson MD, Bukowski RM, Oudard S, Negrier S, Szczylik C, Pili R, Bjarnason GA, et al. Overall survival and updated results for sunitinib compared with interferon alfa in patients with metastatic renal cell carcinoma. J Clin Oncol. 2009;27(22):3584-90.

5. Raman R, Vaena D. Immunotherapy in metastatic renal cell carcinoma: a comprehensive review. Biomed Res Int. 2015;2015:367354.

6. Harshman LC, Drake CG, Choueiri TK. PD-1 blockade in renal cell carcinoma: to equilibrium and beyond. Cancer Immunol Res. 2014;2(12):1132-41.

7. Fishman M, Seigne J. Immunotherapy of metastatic renal cell cancer. Cancer Control. 2002;9(4):293-304

8. Finke JH, Rayman PA, Ko JS, Bradley JM, Gendler SJ, Cohen PA. Modification of the tumor microenvironment as a novel target of renal cell carcinoma therapeutics. Cancer J. 2013;19(4):353-64. 
9. Chen DS, Mellman I. Elements of cancer immunity and the cancer-immune set point. Nature. 2017;541(7637):321-30.

10. Pardoll DM. The blockade of immune checkpoints in cancer immunotherapy Nat Rev Cancer. 2012;12(4):252-64.

11. Weber JS, Kudchadkar RR, Yu B, Gallenstein D, Horak CE, Inzunza HD, Zhao X, Martinez AJ, Wang W, Gibney G, et al. Safety, efficacy, and biomarkers of nivolumab with vaccine in ipilimumab-refractory or -naive melanoma. J Clin Oncol. 2013;31(34):4311-8.

12. Garon EB, Rizvi NA, Hui R, Leighl N, Balmanoukian AS, Eder JP, Patnaik A, Aggarwal C, Gubens M, Horn L, et al. Pembrolizumab for the treatment of non-small-cell lung cancer. N Engl J Med. 2015;372(21):2018-28.

13. Motzer RJ, Rini BI, McDermott DF, Redman BG, Kuzel TM, Harrison MR, Vaishampayan UN, Drabkin HA, George S, Logan TF, et al. Nivolumab for metastatic renal cell carcinoma: results of a randomized phase ॥ trial. J Clin Oncol. 2015;33(13):1430-7.

14. Giraldo NA, Becht E, Pages F, Skliris G, Verkarre V, Vano Y, Mejean A, SaintAubert N, Lacroix L, Natario I, et al. Orchestration and prognostic significance of immune checkpoints in the microenvironment of primary and metastatic renal cell Cancer. Clin Cancer Res. 2015;21(13):3031-40.

15. Bubb RS, Komaki R, Hachiya T, Milas I, Ro JY, Langford L, Sawaya R, Putnam $\mathrm{JB}$, Allen $\mathrm{P}$, Cox JD, et al. Association of Ki-67, p53, and bcl-2 expression of the primary non-small-cell lung cancer lesion with brain metastatic lesion. Int J Radiat Oncol Biol Phys. 2002;53(5):1216-24.

16. Das M, Zhu C, Kuchroo VK. Tim-3 and its role in regulating anti-tumor immunity. Immunol Rev. 2017;276(1):97-111.

17. Gleason MK, Lenvik TR, McCullar V, Felices M, O'Brien MS, Cooley SA, Verneris MR, Cichocki F, Holman CJ, Panoskaltsis-Mortari A, et al. Tim-3 is an inducible human natural killer cell receptor that enhances interferon gamma production in response to galectin-9. Blood. 2012;119(13):3064-72.

18. Gorman JV, Starbeck-Miller G, Pham NL, Traver GL, Rothman PB, Harty JT, Colgan JD. Tim-3 directly enhances CD8 T cell responses to acute listeria monocytogenes infection. J Immunol. 2014;192(7):3133-42.

19. Lee J, Su EW, Zhu C, Hainline S, Phuah J, Moroco JA, Smithgall TE, Kuchroo VK, Kane LP. Phosphotyrosine-dependent coupling of Tim-3 to T-cell receptor signaling pathways. Mol Cell Biol. 2011;31(19):3963-74.

20. Nakae S, likura M, Suto H, Akiba H, Umetsu DT, Dekruyff RH, Saito H, Galli SJ. TIM-1 and TIM-3 enhancement of Th2 cytokine production by mast cells. Blood. 2007;110(7):2565-8.

21. Callea M, Albiges L, Gupta M, Cheng SC, Genega EM, Fay AP, Song J, Carvo I, Bhatt RS, Atkins MB, et al. Differential expression of PD-L1 between primary and metastatic sites in clear-cell renal cell carcinoma. Cancer Immunol Res. 2015;3(10):1158-64.

22. Zhou E, Huang Q, Wang J, Fang C, Yang L, Zhu M, Chen J, Chen L, Dong M. Up-regulation of Tim-3 is associated with poor prognosis of patients with colon cancer. Int J Clin Exp Pathol. 2015;8(7):8018-27.

23. Yuan J, Jiang B, Zhao H, Huang Q. Prognostic implication of TIM-3 in clear cell renal cell carcinoma. Neoplasma. 2014;61(1):35-40.

24. Yang M, Yu Q, Liu J, Fu W, Cao Y, Yu L, Shao S, Wang X, Niu H, Wang Y. Tcell immunoglobulin mucin-3 expression in bladder urothelial carcinoma: Clinicopathologic correlations and association with survival. J Surg Oncol. 2015;112(4):430-5

25. Piao $Y R$, Piao $L Z$, Zhu LH, Jin ZH, Dong XZ. Prognostic value of $T$ cell immunoglobulin mucin-3 in prostate cancer. Asian Pac J Cancer Prev. 2013;14(6):3897-901.

26. Komohara Y, Morita T, Annan DA, Horlad H, Ohnishi K, Yamada S, Nakayama T, Kitada S, Suzu S, Kinoshita I, et al. The coordinated actions of TIM-3 on Cancer and myeloid cells in the regulation of Tumorigenicity and clinical prognosis in clear cell renal cell carcinomas. Cancer Immunol Res. 2015;3(9): 999-1007.

27. Farren MR, Mace TA, Geyer S, Mikhail S, Wu C, Ciombor K, Tahiri S, Ahn D, Noonan AM, Villalona-Calero $M$, et al. Systemic immune activity predicts overall survival in treatment-naive patients with metastatic pancreatic Cancer. Clin Cancer Res. 2016;22(10):2565-74.

28. Wu J, Lin G, Zhu Y, Zhang H, Shi G, Shen Y, Zhu Y, Dai B, Ye D. Low TIM3 expression indicates poor prognosis of metastatic prostate cancer and acts as an independent predictor of castration resistant status. Sci Rep. 2017;7(1): 8869.

29. van Esch EM, van Poelgeest MI, Kouwenberg S, Osse EM, Trimbos JB, Fleuren GJ, Jordanova ES, van der Burg SH. Expression of coinhibitory receptors on T cells in the microenvironment of usual vulvar intraepithelial neoplasia is related to proinflammatory effector T cells and an increased recurrence-free survival. Int J Cancer. 2015;136(4):E95-106.

30. Sun QY, Qu CH, Liu JQ, Zhang P, Yao J. Down-regulated expression of Tim-3 promotes invasion and metastasis of colorectal cancer cells. Neoplasma. 2017;64(1):101-7.

31. Reig Torras O, Marin Aguilera M, Jimenez N, Paré L, Galvan P, Mallofre C, Prat A, Mellado Gonzalez B. Immune expression profile and sunitinib benefit in metastatic clear cell renal cell carcinoma (ccRCC). Ann Oncol. 2017; 28(suppl_5, 1):mdx371.052

32. Hou N, Ma J, Li W, Zhao L, Gao Q, Mai L. T-cell immunoglobulin and mucin domain-containing protein-3 and galectin-9 protein expression: potential prognostic significance in esophageal squamous cell carcinoma for Chinese patients. Oncol Lett. 2017;14(6):8007-13.

\section{Ready to submit your research? Choose BMC and benefit from:}

- fast, convenient online submission

- thorough peer review by experienced researchers in your field

- rapid publication on acceptance

- support for research data, including large and complex data types

- gold Open Access which fosters wider collaboration and increased citations

- maximum visibility for your research: over $100 \mathrm{M}$ website views per year

At BMC, research is always in progress.

Learn more biomedcentral.com/submissions 